\title{
Experimental measurement and evaluation of the noise generated by three transmissions by synchronous belts of type AT10, BAT10 and SFAT10
}

Merghache Sidi Mohammed ( $\nabla$ sidimohamedmerghache@gmail.com )

Centre Universitaire de Tissemsilt https://orcid.org/0000-0001-8117-2530

Hamdi Amine

Centre Universitaire de Tissemsilt

Fernini Brahim

Centre Universitaire de Tissemsilt

Original Article

Keywords: Belt, Torque, Noise, Setting tension, Angular speed

Posted Date: June 5th, 2020

DOI: https://doi.org/10.21203/rs.3.rs-31638/v1

License: (c) (1) This work is licensed under a Creative Commons Attribution 4.0 International License.

Read Full License 


\title{
Experimental measurement and evaluation of the noise generated by three transmissions by synchronous belts of type AT10, BAT10 and
} SFAT10

\author{
Merghache Sidi Mohammed $^{\text {a*}}$, Hamdi Amine ${ }^{\text {a }}$, Fernini Brahim ${ }^{a}$, \\ ${ }^{a}$ Laboratory of Mechanical Engineering, Materials and Structures, University Center of Tissemsilt -38000 Tissemsilt- \\ Algeria.
}

\begin{abstract}
Synchronous belt drives combine the advantages of simple belt drives (flat, trapezoidal or ridged) due to their low weight, low maintenance, large linear speed ranges and high transmission ratios with the advantages of chains: absence sliding, synchronized transmission of speed, low tensioning, etc. Thanks to the toothing of the belt which enters the corresponding one of the synchronous pulleys, there is direct transmission of the power without sliding as between two gears. This article develops an experimental study which makes it possible to see the influence of the angular speed, the engine torque and the setting tension on the impact noise of the belt teeth on the pulley teeth during meshing and vibrations of the free strands of the belt. We have measured the noise generated by three transmissions by synchronous belts of type AT10, BAT10 and SFAT10.
\end{abstract}

Keywords: Belt, Torque, Noise, Setting tension, Angular speed. 


\begin{tabular}{|ll|}
\hline Nomenclature & \\
$F_{N}$ & Nominal transmissible tangential force [N] by the armature (N) \\
$F_{T}$ & Tangential force [N] \\
$F_{P t}$ & Pre-tension force during assembly [N] \\
$F_{T / Z}$ & Tangential force transmissible [N] by a tooth engaged by $10 \mathrm{~mm}$ of belt width \\
$P$ & Power [kW] \\
$V$ & Speed [m/s] \\
$e$ & Centre distance [mm] \\
$B_{b}, B_{p}$ & Belt width and pulley width [mm] \\
$d_{k 1}, d_{k 2}$ & Outside diameter of the small pulley [mm] \\
$d_{01}$ & pitch diameter [mm] \\
$t$ & Pitch [mm] \\
$Z_{B}$ & Number of belt teeth \\
$Z_{e}$ & Number of teeth engaged on the driving pulley (max. 12 for calculation). \\
$f$ & Frequency [Hz] \\
$Z_{1}, Z_{2}$ & Number of teeth of the driving pulley and drive pulley \\
$k$ & Constant for measuring pretension $k=2.5$ \\
$L_{b}$ & The width of the belt [mm] \\
$L_{p}$ & The width of the pulley [mm] \\
$T$ & The vectors to create the filter data y tension [N] \\
$C_{1}, H_{2}$ & \\
\hline &
\end{tabular}




\section{Introduction}

Transmission system noise can come from many components. Almost every moving part in a system is capable of generating noise - including bearings, motors and belts. Potential noise from other components should be taken into account when trying to solve a noise problem. Undersized, poorly lubricated, worn, or misaligned bearings can generate noise. Rotating components can create an air movement that can produce noise. A weak structure can bend under load and cause misalignment which will increase belt flapping and tooth interference, which may cause noise. Like any other power transmission system, synchronous belt transmissions are capable of high noise levels. All synchronous belts generate noise at the engagement frequency and its harmonics when the teeth of the belt come in and out of the pulley grooves. Since belt noise tends to increase with tension and interference, the more precise the tension and alignment, the less noise the transmission will tend to make. Many different factors affect the noise of belt drive Fig.1.

A toothed belt transmission emits several types of noise. Running noise is the most studied in the literature. This noise is defined in frequency by the fundamental and the harmonics of the frequency of engagement of the belt teeth. Its intensity in decibels is proportional to the speed of rotation of the transmission. The main causes are the impact of the belt teeth on the pulley teeth during meshing and the transverse vibrations of the free strands of the belt. A lot of research was started 70 years ago in both theoretical and experimental directions to define and understand the acoustic behavior of synchronous belts and therefore optimize the service life. This research has really helped to pass the problem scientifically and succeeded in clarifying certain points. 
In 2018, Fedorko et al [1] proposed a methodology for the identification and analysis of noise sources in continuous belt conveyor systems using an acoustic camera. Their objective is to identify sources of noise as an indicator of the occurrence of unfavorable operational situations. They have shown that this method of visualizing sound sources is fully applicable in the field of continuous transport systems. To our knowledge, only one study was obtained in 2016, Klimenda et al [2] treated the measurement of noise and vibrations of four types of rollers for a belt conveyor. They gave a process for measuring the noise and vibrations of the different types of rollers; this process is based on the variation of the three high acceleration values as a function of the vibration frequency in the different directions ( $\mathrm{x}, \mathrm{y}$, and $\mathrm{z}$ ). In addition, Menderes [3] presents a dynamic multi-body system model of two commercial front-loading drum washing machines designed for the analysis of the acoustic performances linked to washing and spinning. This model was built using a theoretical-experimental methodology. He used a microphone and a PC to measure the noise and acceleration of this washing machine system.

In this regard, Chen et al [4] have decomposed and formulated the sources of noise of the synchronous belt by an analysis of the impact dynamics of the tooth-belt-pinion interface. They developed a noise model that is based on air pumping and flow ejection during the engagement of the belt sprocket tooth by the Lighthill equation. The proposed model makes it possible to distinguish structural impact noise, noise induced by friction and noise induced by air flow with their properties. In [2012] Chen et al [5] they presented an experimental study which measures the friction and the associated acoustic behavior is the noise of a rubber belt at low temperature on the basis of a bench pulley test. All the tests were carried out in a cold room with temperatures of $23^{\circ} \mathrm{C}$ and $-20^{\circ} \mathrm{C}$ respectively, and under dry and wet-cold conditions. 
On the other hand, Sheng et al [6] presented an experimental characterization and analysis of friction and vibro-acoustic behavior of ribbed rubber belts of automobiles under wet conditions. They quantify the effects of wet conditions on the friction and noise of these belts during start-up. Therefore, Shu and Liang [7] have presented a method, hierarchical diagnosis as well as a coherent analysis of the power spectrum to identify the sources of complex noise of diesel engines. They found that the source of noise comes mainly from the low frequency transmission belt, machine noise from the oil pump, gear and valve mechanism, etc. for this; they have developed strategies to reduce this noise. Next, Fang and Ling [8] examined the effects of noise reduction from six tree belts. They placed an amplifier in front of each belt of trees. Then, they installed a sound level meter at different heights and distances behind these tree belts. They developed a multiple regression model that demonstrates the order of importance of visibility, the height and width of the belt shaft, the height of the receiver and the noise source, and the distance between the noise source and the receiver with respect to the relative attenuation. Although, Tokoro et al [9.10] presented two studies, the first one, they study the cause of the appearance of high frequency noise which is one of the sounds of the timing belt of a real engine. They identified that this noise is generated by discontinuous slippage and the air flow retained between the belt and the pulley. The noise estimation and reduction methods of these belts designed on the basis of these results have proved to be effective. The second study, they presented a study which observed the generation mechanism and the method of reduction of transverse vibrations as the cause of the mesh order noise which is one of the sounds of the timing belt. The results of their study prove that suppressing the excitation force is effective in reducing transverse vibrations. On the other hand, Koyama and Marshek [11] presented a technical document on load distribution, service life, noise, transmission errors and jumping characteristics of toothed belts. 
In this article, we used a test bench to measure the noise produced by three pulley-belt transmissions of the AT10, BAT10 and SFAT10 type. Several experiments have been carried out with several parameters: the angular speed 500 to $2500 \mathrm{rpm}$ with a step of $500 \mathrm{rpm}$, the torque from 0 to $50 \mathrm{Nm}$ with a step of $25 \mathrm{Nm}$ and setting tension from 400 to $600 \mathrm{~N}$ with a step of 100 N. Last, we subjected the results of these noises to a comparison. This document is organized as follows. In section 2 is devoted to determining the parameters of these Binder Magnetic belts. Section 3 presents the measurement of noise from pulley belt transmissions by experimental bearing. Section 4 is the comparison of the results of these noises. Finally, in section 5, conclusions are drawn.

\section{Structure of BINDER MAGNETIC belt-pulley transmission}

A toothed belt is an endless belt in the longitudinal direction with rectangular cross sections and transverse teeth arranged either on one side (inside or outside) of the belt, or on both sides. In a cross section there is a series of strings sections. They allow the loads to be transmitted and define a primitive line all along the belt. They are wound in pairs and the twist propellers of two successive cords are opposite. In general, the strings are made of fiberglass, polyester, Kevlar and steel. BINDER MANGETIC transmission belts are fitted, as standard, with galvanized steel cables. Thanks to these cables, the belts maintain their length stability (Fig. 2). However, like any metal, steel deforms under stress by following Hooke's law. This law describes the deformations under stress in the phase of elasticity. The elongation of the belt will be proportional to the force in the strand.

In this article, we used toothed pulleys (Fig. 2). They are essential elements of transmission. They ensure proper operation and guarantee an optimal life of the belt. These Binder-Magnetic pulleys 
are manufactured according to the MULCO standard to function optimally with their belts [12]. These standard pulleys are made of aluminum 2017 or of a high-strength aluminum alloy AlHR (7075) for high power transmissions or with high "jolts" (shock or significant torque variation) see Table. 1

\section{Calculation of the parameters of timing belts BINDER MAGNETIC}

BINDER MAGNETIC type timing belts see Fig. 2 are the subject of numerous studies and research with the aim of optimizing their behavior, their characteristics and in particular their lifespan. These toothed belts transmit a power $\boldsymbol{P}$ or more exactly a torque $\boldsymbol{C}$ by the teeth in engagement $Z_{e}$ on the small driving pulley of diameter $\boldsymbol{d}_{\boldsymbol{k} \mathbf{1}}$ rotating at a speed $N_{1}$. Each tooth in engagement is capable of transmitting a maximum force of $F_{T / Z}$. To define a belt, you must therefore know the tangential force $F_{T}$ which will apply to the teeth in engagement $Z_{e}$ and to the

reinforcing cables see Fig.3. The following equations $\mathrm{Eq}$ (1), Eq (2) and Eq (3) are used to determine the power to be transmitted $\boldsymbol{P}$, the torque $\boldsymbol{C}$ and the tangential force $F_{T}$ :

$$
\begin{aligned}
& C=\frac{d_{k 1} \cdot F_{T}}{2 \cdot 10^{3}} \\
& P=\frac{C \cdot N_{1}}{9,55 \cdot 10^{3}} \\
& F_{T}=\frac{19,1 \cdot 10^{6} * P}{N_{1} \cdot d_{k 1}}
\end{aligned}
$$


Depending on the power to be transmitted, the pitch on the graphs [12] is chosen and then the number of teeth in engagement $\boldsymbol{Z}_{\boldsymbol{e}}$ on the smallest pulley $\boldsymbol{d}_{\boldsymbol{k} \mathbf{1}}$. is determined.

$$
Z_{e}=\frac{Z_{1}}{180} \cdot \arccos \left(\frac{\left(Z_{2}-Z_{1}\right) \cdot t}{2 \cdot \pi \cdot e}\right)
$$

We determine the width of the belt $\boldsymbol{B}_{\boldsymbol{b}}$ with the formula below by reading on the charts of [12] to choose the value of $\boldsymbol{F}_{T / Z}$.

$$
B_{b}=\frac{10 \cdot F_{T}}{Z_{e} \cdot F_{T / Z}}
$$

We know that the determination of the belt length $\boldsymbol{L}_{\boldsymbol{c}}$ as a function of the center distance is equal:

$$
L_{c}=\frac{\pi}{2} \cdot\left(d_{01}+d_{02}\right)+2 \cdot e+\frac{\left(d_{02}-d_{01}\right)}{4 \cdot e}
$$

We calculate the resonance frequency to adjust the laying voltage using the TSM3 device by the following equation:

$$
f=\sqrt{\frac{1000 \times F_{P t}}{k \times b \times L_{b}^{2}}}
$$

From the previous equations, we obtain the values of the characteristics of this BINDER MAGNETIC belt drives as a function of the angular speed; the engine torque and the laying tension see Table 2 . 


\section{Experimental method}

The general architecture of the belt test bench is presented in Fig.4. Three synchronous belts of type AT10, BAT10 and SFAT100 and of trapezoidal profile (angle $20^{\circ}$, pitch $10 \mathrm{~mm}$ ) are placed between a driving pulley and another receiver. The overall assembly can be moved perpendicular to the shaft axis for mounting and adjustment of the laying tension for these synchronous belts. Then, all of the elements are tightened to a heavy rigid support. These two pulleys are mounted on two $40 \mathrm{~mm}$ diameter shafts [13]:

- First input shaft connected to a $70 \mathrm{KW}$ power motor with a rigid coupling. This motor allows the rotation speed to be changed.

- Second output shaft connected to a hydraulic brake pump with a rigid coupling. This pump fixes the pressure and thus the resistance torsional moment for a given angular speed.

Note that the contact between the belt and the aluminum alloy pulley takes place at the top of the belt teeth, there are two clearances (the circumferential clearance of $0.5 \mathrm{~mm}$ arrives in the hollow area, the radial clearance of $0.4 \mathrm{~mm}$ between the belt tooth and pulley tooth), the clearance position depends on the relative longitudinal position of belt and pulley teeth due to the torsional moment action. The distance between the pitch line given by the belt cables and the end of the belt tooth is equal to $3.35 \mathrm{~mm}$.

The purpose of the tests was to determine the admissible threshold of transmitted torque and the impact noise of the belt teeth on the pulley teeth during the meshing and the vibrations of the free strands of these toothed belts of the "BINDER MAGNETIC" type, for this we had to test several profiles of belts. Indeed, for each test, the parameters checked are the speed of rotation and the engine torque as well as the laying voltage. 
An electric motor provides motive power while a hydraulic brake provides the resistive torque. For each type of belt, the tests are as follows:

- Angular speeds range from $500 \mathrm{rpm}$ to 2,500 rpm with a step of $500 \mathrm{rpm}$.

- Three setting tension $400 \mathrm{~N}, 500 \mathrm{~N}$ and $600 \mathrm{~N}$, adjustment of this setting tension is done by the TSM3 device (Remote sensor, measurement range: from 7 to $450 \mathrm{~Hz}$, accuracy: \pm $5 \mathrm{~Hz}$, and range of operating temperature: 0 to $50^{\circ} \mathrm{C}$ ). These setting tensions are applied to the web of the belt.

- Motor torque varies from 0 to 50 N.m with a step of 25 N.m.

The tests were done for each combination of test conditions. Only one test is performed for each test condition as preliminary tests have shown the low dispersion of all results (less than 5\%). After the tensioning pose was applied, the belt ran and then resisted when torsion was applied. For an angular speed, the different values of resist at the moment of torsion were applied successively. After the parameter stabilization (the average of $5 \mathrm{~min}$ ), the measurements were made. Each test condition requires approximately ten minutes of testing [14].

The meshing noise is also recorded by a reference microphone COS-11DPT-BK / 1.8 placed 10 millimeters near the pulley and the transmission belt and placed in the meshing entry area. The data were recorded on an acquisition card Fig. 5 of the characteristics: number of channels 8 , number of samples per maximum channel 32000 and max. Weeding frequency $800 \mathrm{kHz}$ and filters were adjusted in relation to signals. 


\section{Experimental results and discussion}

\subsection{Résults}

Numerous results have been collected for these trials. We have decided to present in this article the main trends in curve visualizations. According to the previous analysis, the noise signals of the pulley-belt transmission system can be obtained from the experience of the test bench first. The noise measurement is carried out under nominal conditions. Indeed, each parameter is presented in relation to the angular speed, setting tension and motor torque. All the acoustic signals were captured and stored in a computer, and then via the Fourier transformation, the flat noise spectrum is shown in Fig.6, Fig.7 and Fig.8.

During the processing of the results of measurement of the noise of the belts, parasites appeared which disturbed the signal that is to say that we had completely false noise measurements. The filter procedure was therefore introduced in the processing of the measurements of these noises. Because the filter improves the quality of the signal, we therefore have a noise value corresponding to reality. This filter procedure performs the filtering without phase shift using the coefficients of a filter defined by the FILTFILT function (Zero-phase forward and reverse digital filtering). The filter is described by the following recurring equation:

$$
\begin{aligned}
y(n) & =b(1) \times x(n)+b(2) \times x(n-1)+\cdots \cdots+b(n \times b+1) * x(n-n \times b) \\
& -a(2) \times y(n-1)-\cdots \cdots-a(n \times a+1) \times y(n-n \times a)
\end{aligned}
$$

The data in vector $\boldsymbol{x}$ with the filter described by vectors $\boldsymbol{a}$ and $\boldsymbol{b}$ to create the filtered data $\boldsymbol{y}$ 
Filtering is carried out in two directions so as to eliminate the phase shift introduced by the filter. Edge effects are eliminated by completing the initial vector with length data and the size of the filter. We use the MATLAB FILTER function to perform this filtering. Before using the filter procedure, it is necessary to modify certain lines of the FILTER program. And then Launch the FILTER procedure and give the name of the file that you want to process. Once all the files have been processed, open an MSDOS WINDOW and go to the directory where the text files are stored. The Fig.9, Fig.10 and Fig.11 show the results of the signals filtered from the noise of the toothed belts as a function of the angular speed, setting tension and motor torque.

\subsection{Discussion of results}

The Fig. 12 and Fig. 13 show the noise peaks $\mathrm{H}_{1}$ and $\mathrm{H}_{2}$ of the AT10 belt measured from the three setting tension studied, on which the level and frequency of the noise can be observed as a function of the speed of rotation and the engine torque.

We note that the noise peak let $\mathrm{H}_{1}$ remains almost constant (between $0.51 \mathrm{~dB}$ and $2.85 \mathrm{~dB}$ ) when the angular speed varies from $500 \mathrm{rpm}$ to $1500 \mathrm{rpm}$ for the three driving torques as well as the three setting tensions. Likewise, this peak increases linearly from $1.49 \mathrm{~dB}$ to $30.88 \mathrm{~dB}$ with the increase in the rotation speed between $1500 \mathrm{rpm}$ and $2500 \mathrm{rpm}$, and also with the increase in the laying tension and engine torque. On the other hand, we observe that the noise peak $\mathrm{H}_{2}$ increases linearly from $0.07 \mathrm{~dB}$ to $18.15 \mathrm{~dB}$ when the angular speed increases from $500 \mathrm{rpm}$ to $2500 \mathrm{rpm}$, and it remains pleasant when the setting tension and the motor torque increasing $400 \mathrm{~N}$ to $600 \mathrm{~N}$ and 0 to $50 \mathrm{Nm}$ respectively Similarly, we observe that the noise peak deviation see Table.3:

- $\mathrm{T}=400 \mathrm{~N}$ : $\mathrm{H}_{1}$ varies from $12.85 \mathrm{~dB}$ to $13.77 \mathrm{~dB}$ and $\mathrm{H}_{2}$ varies from $8.84 \mathrm{~dB}$ to $29.53 \mathrm{~dB}$ when the engine torque varies from 0 to 50 N.m. 
- $\mathrm{T}=500 \mathrm{~N}: \mathrm{H}_{1}$ varies from $7.14 \mathrm{~dB}$ to $11.83 \mathrm{~dB} \mathrm{H}_{2}$ varies from $10.64 \mathrm{~dB}$ to $26.03 \mathrm{~dB}$ when the engine torque varies from 0 to 50 N.m.

- $\mathrm{T}=600 \mathrm{~N}: \mathrm{H}_{1}$ varies from $7.10 \mathrm{~dB}$ to $17.90 \mathrm{~dB} \mathrm{H}_{2}$ varies from $17.36 \mathrm{~dB}$ to $22.66 \mathrm{~dB}$ when the engine torque varies from 0 to 50 N.m.

Fig.12 and Fig.13 illustrate the noise peaks $\mathrm{H}_{1}$ and $\mathrm{H}_{2}$ of the BAT10 belt measured as a function of the speed of rotation, the setting tension and the engine torque.

According to these results, for this BAT10 belt, we note that to increase the noise peak $\mathrm{H}_{1}$ from $52.04 \mathrm{~dB}$ to $85.45 \mathrm{~dB}$, it is therefore necessary to increase the angular speed varies from $500 \mathrm{rpm}$ to $2500 \mathrm{rpm}$, the torque motor from 0 to $50 \mathrm{Nm}$ and the setting tension from $400 \mathrm{~N}$ to $600 \mathrm{~N}$.

On the other hand, we observe that the noise peak $\mathrm{H}_{2}$ increases from $33.98 \mathrm{~dB}$ to $79.64 \mathrm{~dB}$ when the angular speed increases from $500 \mathrm{rpm}$ to $2500 \mathrm{rpm}$. Similarly, we observe that the noise peak deviation sees Table.4:

- $\mathrm{T}=400 \mathrm{~N}$ : $\mathrm{H}_{1}$ varies from $20.06 \mathrm{~dB}$ to $28.43 \mathrm{~dB}$ and $\mathrm{H}_{2}$ varies from $40.34 \mathrm{~dB}$ to $28.15 \mathrm{~dB}$ when the engine torque varies from 0 to 50 N.m.

- $\mathrm{T}=500 \mathrm{~N}: \mathrm{H}_{1}$ varies from $25.42 \mathrm{~dB}$ to $32.53 \mathrm{~dB}$ and $\mathrm{H}_{2}$ varies from $39.55 \mathrm{~dB}$ to $31.50 \mathrm{~dB}$ when the engine torque varies from 0 to 50 N.m.

- $\mathrm{T}=600 \mathrm{~N}$ : $\mathrm{H}_{1}$ varies from $20.65 \mathrm{~dB}$ to $27.35 \mathrm{~dB}$ and $\mathrm{H}_{2}$ varies from $39.18 \mathrm{~dB}$ to $30.37 \mathrm{~dB}$ when the engine torque varies from 0 to 50 N.m.

The experimental results of the measurement of acoustic noise with respect to the angular speed, setting tension and motor torque are given in Fig.16 and Fig.17. 
Finally, as we have seen in the results of the previous SFAT10 belt measurements, we see that the red and black curves are less than the blue curve when the rotation speed varies from $500 \mathrm{rpm}$ to $2500 \mathrm{rpm}$. This means that the noise peak increases with increasing rotation angular and engine torque. And also note that this noise remains constant when the setting tension increases. On the other hand, we observe that the noise peak $\mathrm{H} 2$ increases from $33.98 \mathrm{~dB}$ to $85.93 \mathrm{~dB}$ when the angular speed increases from $500 \mathrm{rpm}$ to $2500 \mathrm{rpm}$. Indeed, we notice that the noise peak deviation sees Table.5:

- $\mathrm{T}=400 \mathrm{~N}: \mathrm{H}_{1}$ varies from $13.38 \mathrm{~dB}$ to $27.85 \mathrm{~dB}$ and $\mathrm{H}_{2}$ varies from $26.52 \mathrm{~dB}$ to $38.38 \mathrm{~dB}$ when the engine torque varies from 0 to 50 N.m.

- $\mathrm{T}=500 \mathrm{~N}: \mathrm{H}_{1}$ varies from $17.75 \mathrm{~dB}$ to $29.63 \mathrm{~dB}$ and $\mathrm{H}_{2}$ varies from $17.94 \mathrm{~dB}$ to $27.17 \mathrm{~dB}$ when the engine torque varies from 0 to 50 N.m.

- $\mathrm{T}=600 \mathrm{~N}: \mathrm{H}_{1}$ varies from $26.33 \mathrm{~dB}$ to $28.14 \mathrm{~dB}$ and $\mathrm{H}_{2}$ varies from $32.07 \mathrm{~dB}$ to $37.62 \mathrm{~dB}$ when the engine torque varies from 0 to 50 N.m.

\section{Conclusion}

Since the noise of a machine is generally only a by-product of its operating mode, the variety of acoustic problems posed by all of the machines encountered in the mechanical industries is practically limitless. Our purpose cannot therefore pretend to review all these problems but it will rather seek to identify some general considerations in order to guide the approach of technicians who are confronted with the study of machine noise. At the end of this study, we highlighted an experimental analysis for the purpose of measuring the noise delirious by three pulley-belt transmissions of type AT10, BAT10 and SFAT10. Indeed, the tests carried out made it possible to see the influence of the angular speed, the engine torque and the setting tension on the acoustic 
behavior of the three transmissions. The results obtained in this work allow us to draw the following conclusions:

- We notice the noise taking an almost almost constant pace for the AT10 belt. It increases slightly for the SFAT10 and BAT10 cases.

- However, the BAT10 belt gives approximately the same noise values as the SFAT10 belt.

- Note for the SFAT10 belt that the maximum noise is given for H2 because the teeth are only separated by half of the pitch and the actual engagement frequency is double.

- Finally, the case of the SFAT10 belt is $42 \mathrm{~dB}$ at $55 \mathrm{~dB}$ more than the case of the AT10 belt.

- The noise netting depends on the tooth netting, the tooth circular shape gives wide noise reduction 


\section{Références bibliographiques}

[1] Fedorko, G., Liptai, P., Molnár, V. (2018). Proposal of the methodology for noise sources identification and analysis of continuous transport systems using an acoustic camera. Engineering Failure Analysis, Volume 83, Pages 30-46, 2018, DOI:10.1016/j.engfailanal.2017.09.011

[2] Klimenda. F, Kampo. J, Hejma. P, Vibration Measurement of Conveyor Rollers. Procedia Engineering, Volume 136, Pages 198-203, 2016, DOI:10.1016/j.proeng.2016.01.197

[3] Kalkat. M, Experimentally vibration and noise analysis of two types of washing machines with a proposed neural network predictor, Measurement, Volume 47, Pages 184-192, 2014, DOI:10.1016/j.measurement.2013.08.039

[4] Chen. G, Zheng. H, Qatu. M, Decomposition of noise sources of synchronous belt drives, Journal of Sound and Vibration, Volume 332, Pages 2239-2252, 2013, DOI:10.1016/j.jsv.2012.11.030

[5] Chen. G, Lee. J. H, Narravula. V, Kitchin. T, Friction and noise of rubber belt in low temperature condition: The influence of interfacial ice film, Cold Regions Science and Technology, Volume 71, Pages 95-101, 2012, DOI:10.1016/j.coldregions.2011.10.007

[6] Sheng. G, Lee. J. H, Narravula. V, Song. D, Experimental characterization and analysis of wet belt friction and the vibro-acoustic behavior. Tribology International, Volume 44, Issue 3, Pages 258-265, 2011, DOI:10.1016/j.triboint.2010.10.025

[7] Shu. G, Liang. X, (2007). Identification of complex diesel engine noise sources based on coherent power spectrum analysis. Mechanical Systems and Signal Processing, Volume 21, Issue 1, Pages 405-416, 2007, DOI:10.1016/j.ymssp.2006.06.001 
[8] Fang. C. F, Ling. D. L, Guidance for noise reduction provided by tree belts, Landscape and Urban Planning, Volume 71, Pages 29-34, 2005, DOI:10.1016/j.landurbplan.2004.01.005

[9] Tokoro. H, Nakamura. M, Sugiura. N, Tani. H, Shuku. T, Analysis of high frequency noise in engine timing belt, JSAE Review, Volume 19, Issue 1, Pages 33-38, 1998, DOI:10.1016/S0389-4304(97)00046-5

[10] Tokoro. H, Nakamura. M, Sugiura. N, Tani. H, Shuku. T, Analysis of transverse vibration in engine timing belt, JSAE Review, Volume 18, Issue 1, Pages 33-38, 1997, DOI:10.1016/S0389-4304(96)00049-5

[11] Koyama. T, Marshek. K. M, Toothed belt drives-Past, present and future, Mechanism and Machine Theory, Volume 23, Issue 3, Pages 227-241, 1988, DOI:10.1016/0094$114 \mathrm{X}(88) 90108-5$

[12] BINDER MAGNETIC, Catalogue for timing belt choice.

[13] MERGHACHE. S, GHERNAOUT. A, Influence of temperature on the performance toothed belts-binder magnetic, European Scientific Journal, volume.9, Issue 33, Page 206-212, 2013.

[14] MERGHACHE. S, GHERNAOUT. A, Experimental and numerical study of heat transfer through a synchronous belt transmission type AT10, Applied Thermal Engineering, Volume 127, Page 705-717, 2017, DOI: 10.1016/j.applthermaleng.2017.08.079 


\section{Figures}

\section{Belt speed}

- The noise generally increases with the speed of the belts.

\section{Pulley size}

- Very small pulleys tend to produce more noise due to the polygonal effect.

\section{Belt tension}

- Noise tends to increase with dynamic belt tension

\section{Belt width}

- Belt noise tends to increase with belt width

\section{Figure 1}

Different factors affect noise of belt drive.

-a-

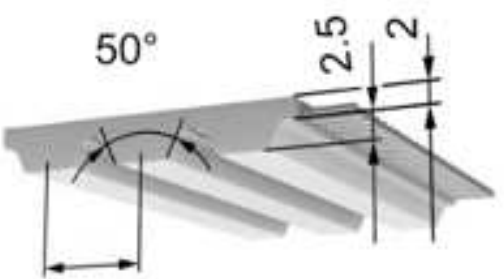

10

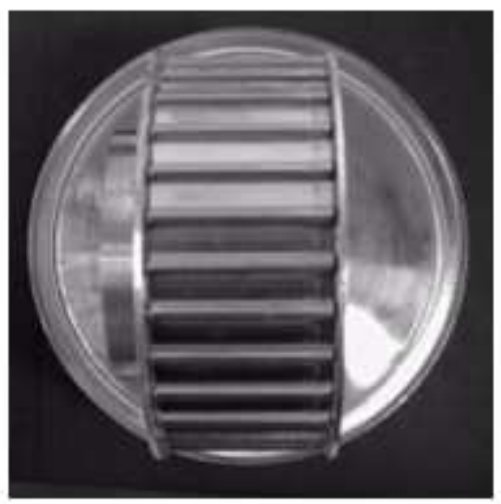

$-b-$
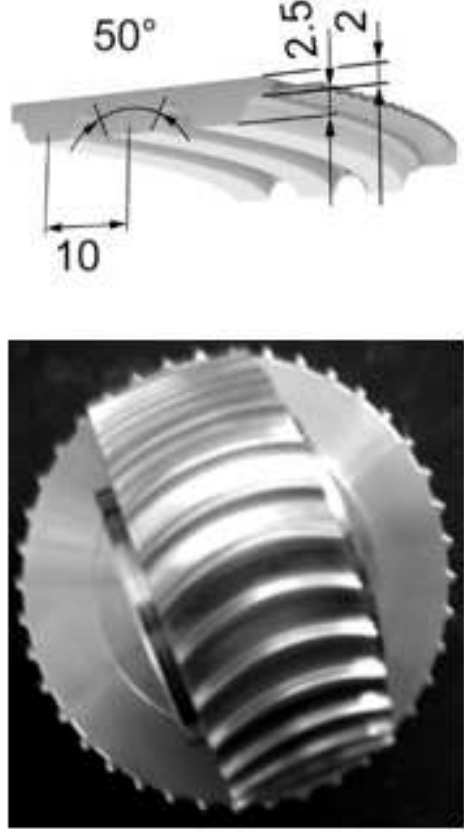

$-c-$
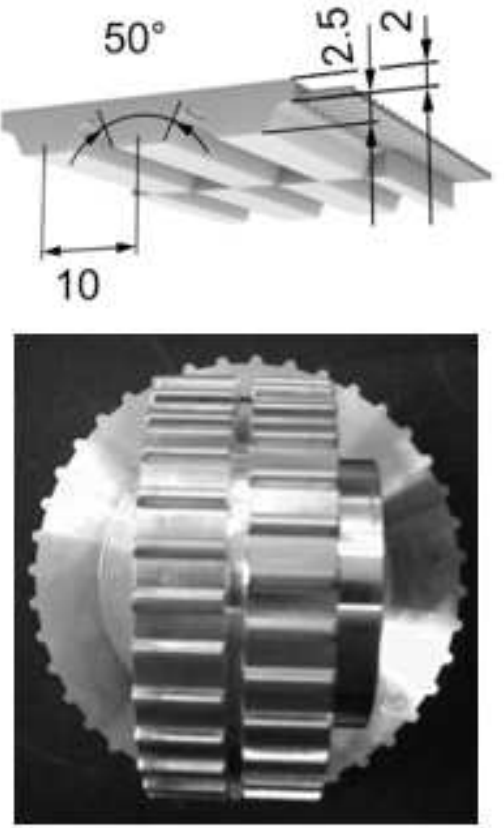

\section{Figure 2}

Distribution belts and pulleys Magnetic Binder: a- AT10 (profile with spur teeth), b- BAT10 (profile in with circular teeth), c- SFAT10 (profile with shift half teeth). 


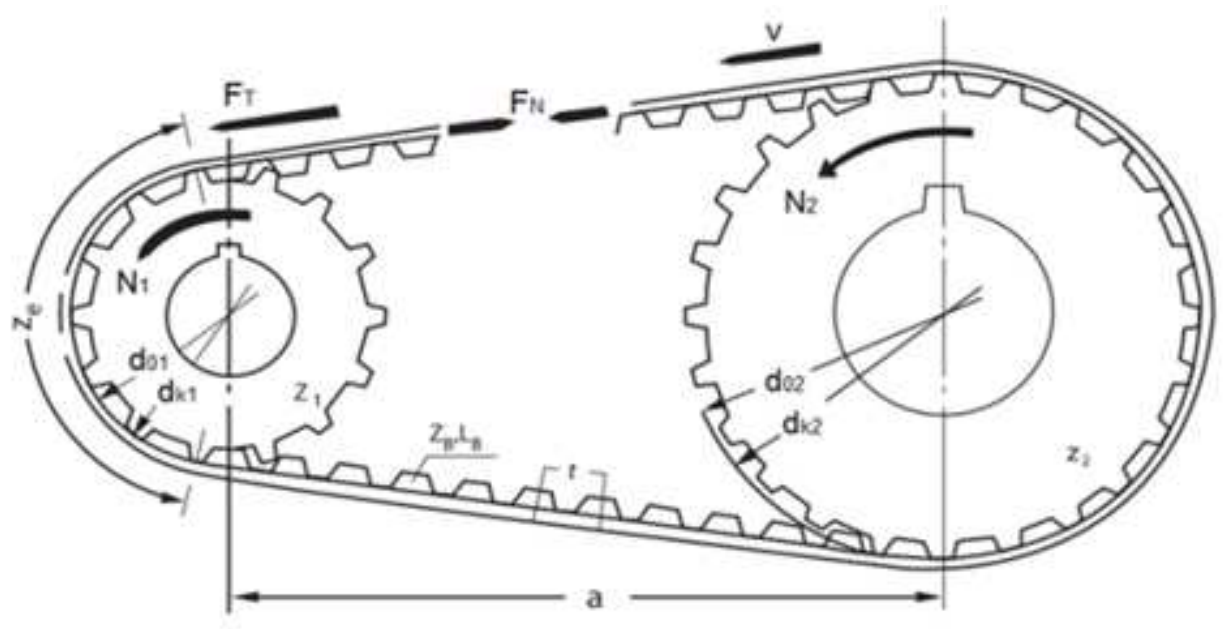

Figure 3

Parameters of the Binder Magnetic timing belt.

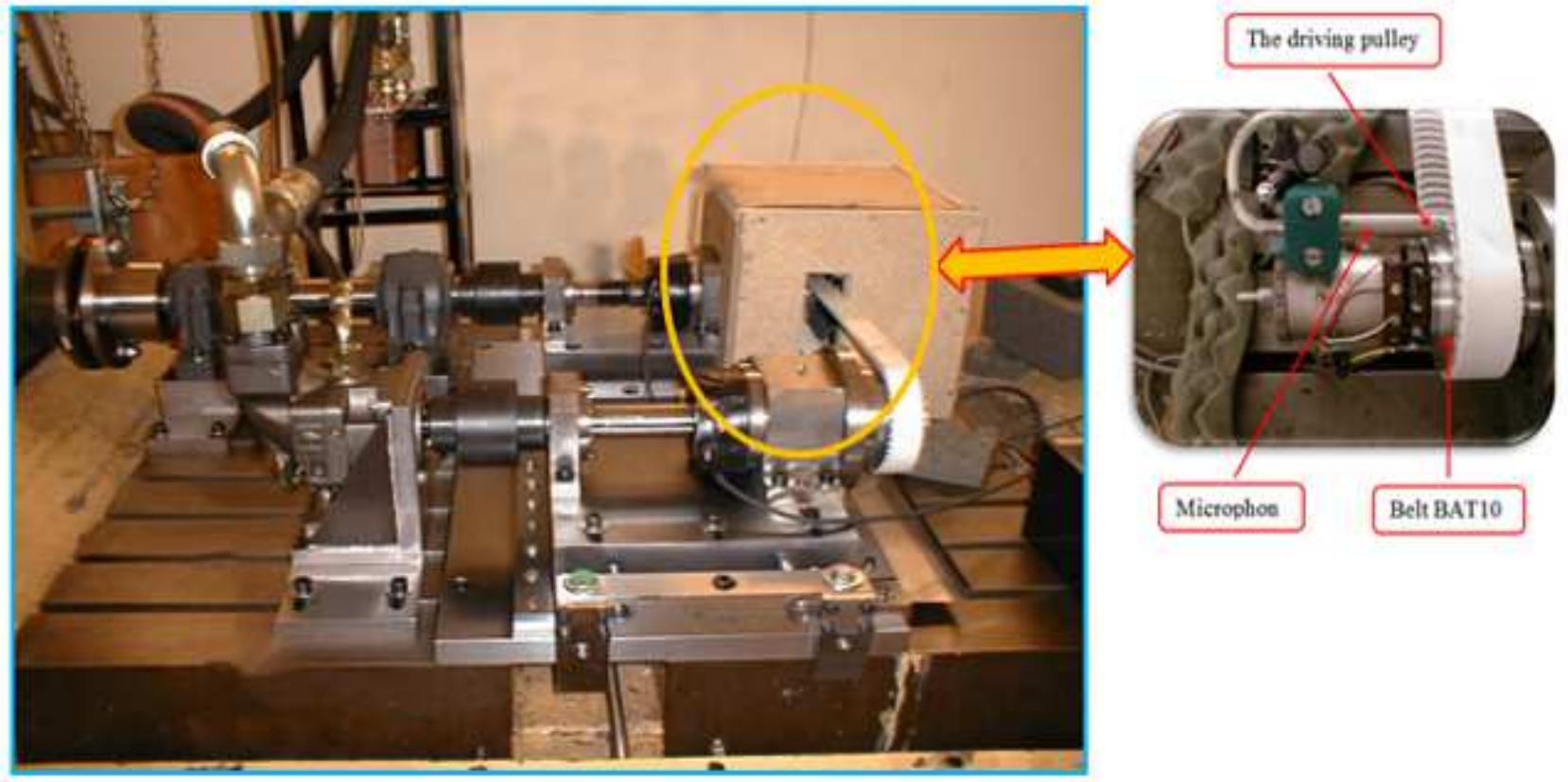

Figure 4

General view of the test bench for transmission belts. 


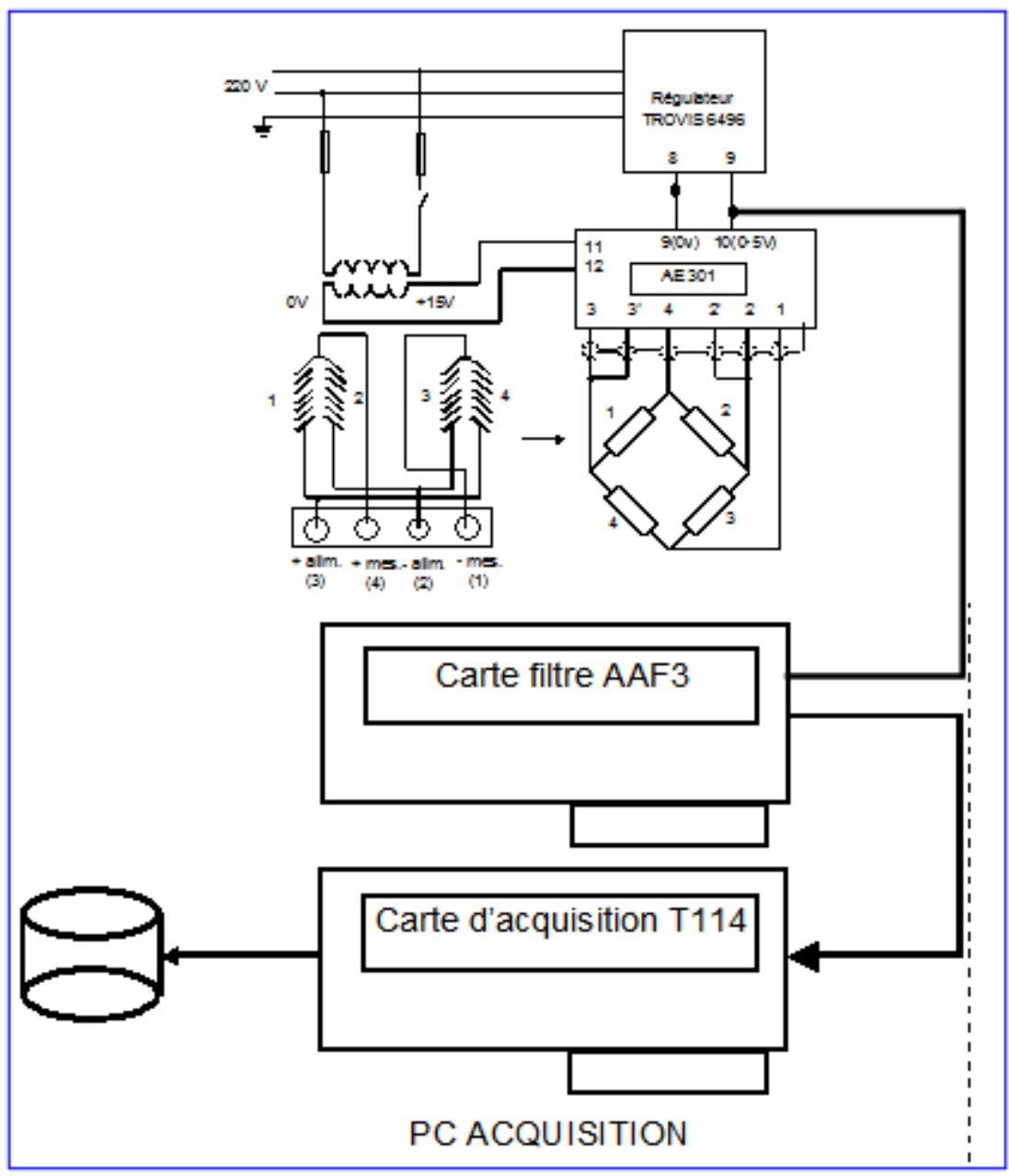

Figure 5

Diagram of the acquisition chain.
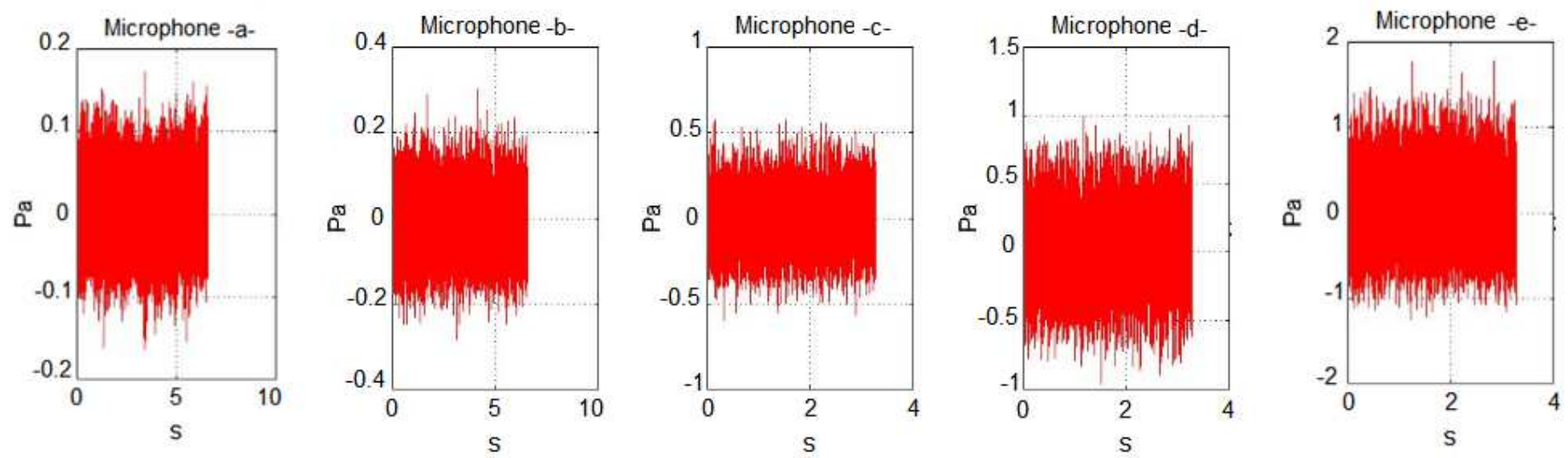

Figure 6

Results of noise measurement by the microphone for the AT10 belt with a setting tension $\mathrm{T}=400 \mathrm{~N}$ and torque $\mathrm{C}=25 \mathrm{~N} \cdot \mathrm{m}$ : $\mathrm{a}-\mathrm{N}=500 \mathrm{rpm}, \mathrm{b}-\mathrm{N}=1000 \mathrm{rpm}, \mathrm{c}-\mathrm{N}=1500 \mathrm{rpm}, \mathrm{d}=\mathrm{N}=2000 \mathrm{rpm}, \mathrm{c}-\mathrm{N}=2500 \mathrm{rpm}$ 

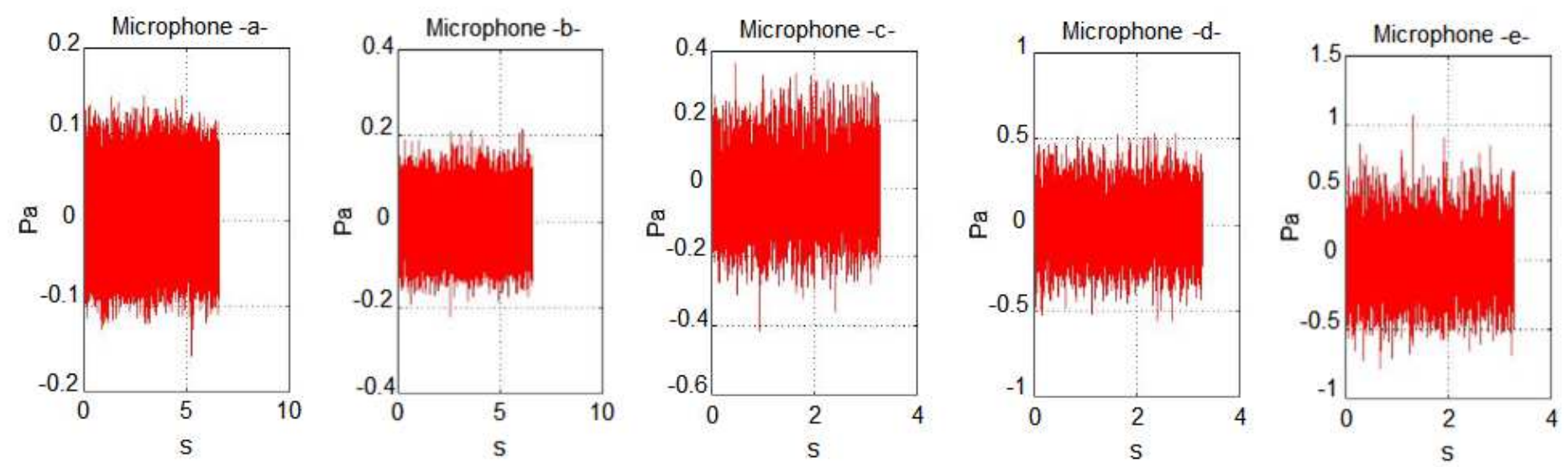

Figure 7

Results of noise measurement by the microphone for the BAT10 belt with a setting tension $\mathrm{T}=400 \mathrm{~N}$ and torque $\mathrm{C}=25 \mathrm{~N} \cdot \mathrm{m}$ : $\mathrm{a}-\mathrm{N}=500 \mathrm{rpm}, \mathrm{b}-\mathrm{N}=1000 \mathrm{rpm}, \mathrm{c}-\mathrm{N}=1500 \mathrm{rpm}, \mathrm{d}=\mathrm{N}=2000 \mathrm{rpm}, \mathrm{c}-\mathrm{N}=2500 \mathrm{rpm}$
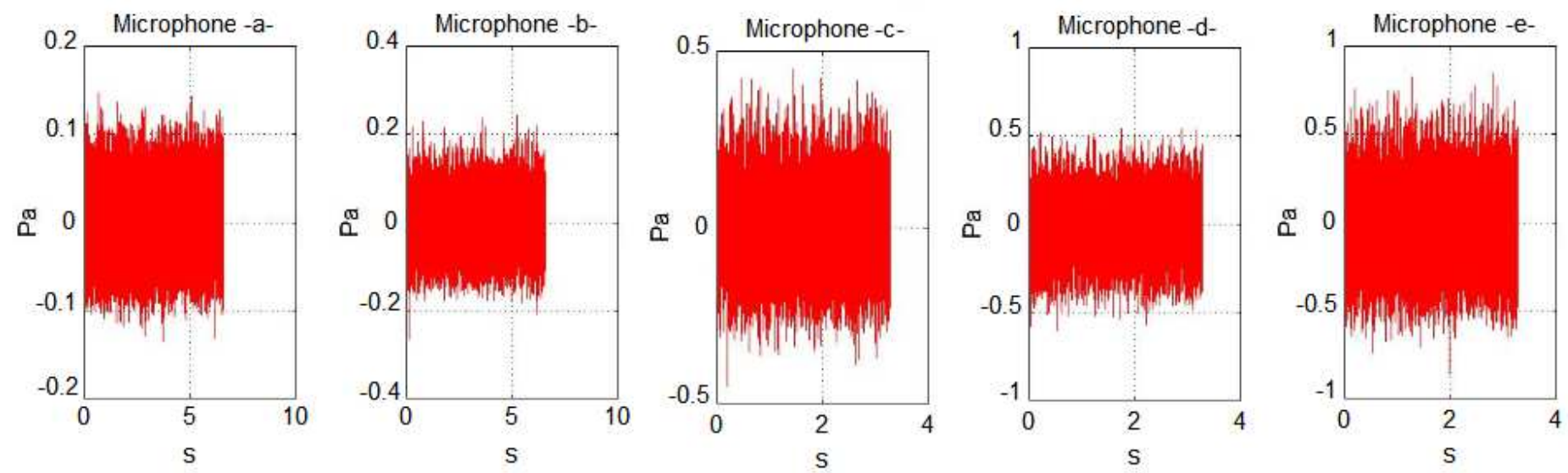

\section{Figure 8}

Results of noise measurement by the microphone for the SFAT10 belt with a setting tension $\mathrm{T}=400 \mathrm{~N}$ and torque $\mathrm{C}=25 \mathrm{~N} \cdot \mathrm{m}$ : $\mathrm{a}-\mathrm{N}=500 \mathrm{rpm}, \mathrm{b}-\mathrm{N}=1000 \mathrm{rpm}, \mathrm{c}-\mathrm{N}=1500 \mathrm{rpm}, \mathrm{d}=\mathrm{N}=2000 \mathrm{rpm}, \mathrm{c}-\mathrm{N}=2500$ rpm
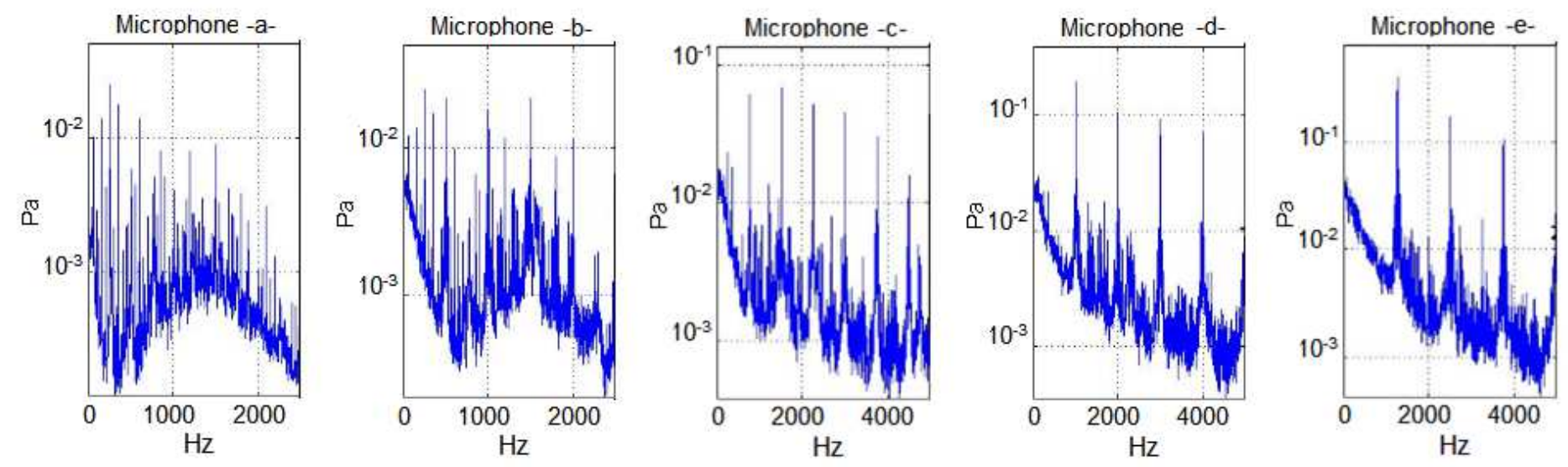

Figure 9 
Results of noise filtering measurement by microphone of the belt AT10 with a setting tension $\mathrm{T}=400 \mathrm{~N}$ and torque $\mathrm{C}=25 \mathrm{~N} \cdot \mathrm{m}$ : $\mathrm{a}-\mathrm{N}=500 \mathrm{rpm}, \mathrm{b}-\mathrm{N}=1000 \mathrm{rpm}, \mathrm{c}-\mathrm{N}=1500 \mathrm{rpm}, \mathrm{d}=\mathrm{N}=2000 \mathrm{rpm}, \mathrm{c}-\mathrm{N}=2500$ rpm
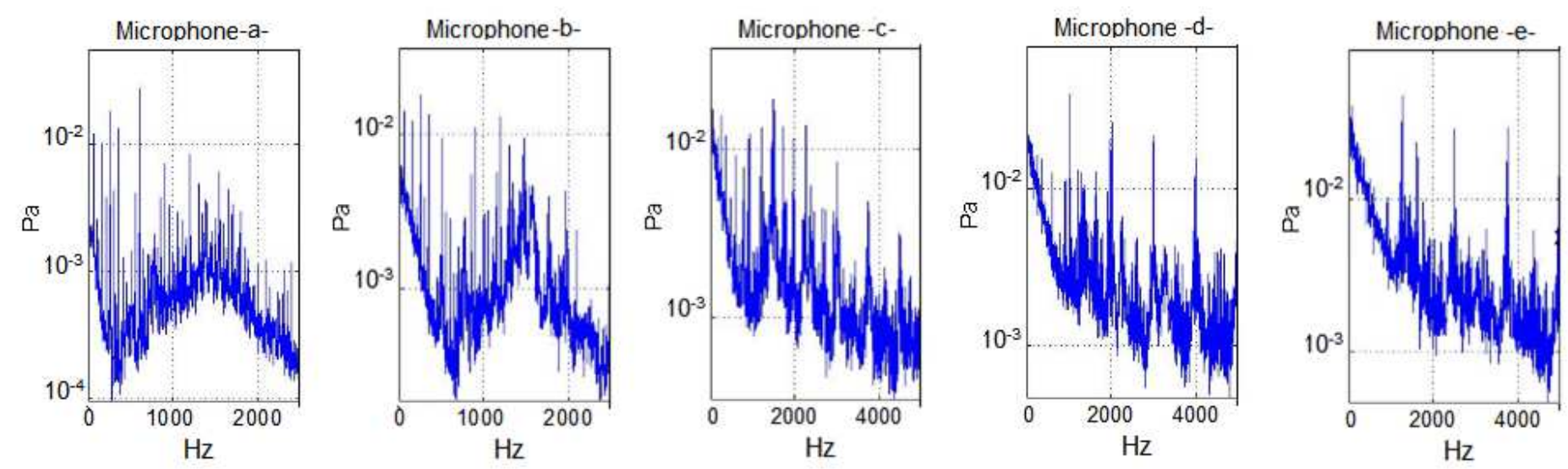

Figure 10

Results of noise filtering measurement by microphone of the belt BAT10 with a setting tension $\mathrm{T}=400 \mathrm{~N}$ and torque $\mathrm{C}=25 \mathrm{~N} \cdot \mathrm{m}$ : $\mathrm{a}-\mathrm{N}=500 \mathrm{rpm}, \mathrm{b}-\mathrm{N}=1000 \mathrm{rpm}, \mathrm{c}-\mathrm{N}=1500 \mathrm{rpm}, \mathrm{d}=\mathrm{N}=2000 \mathrm{rpm}, \mathrm{c}-\mathrm{N}=2500$ rpm
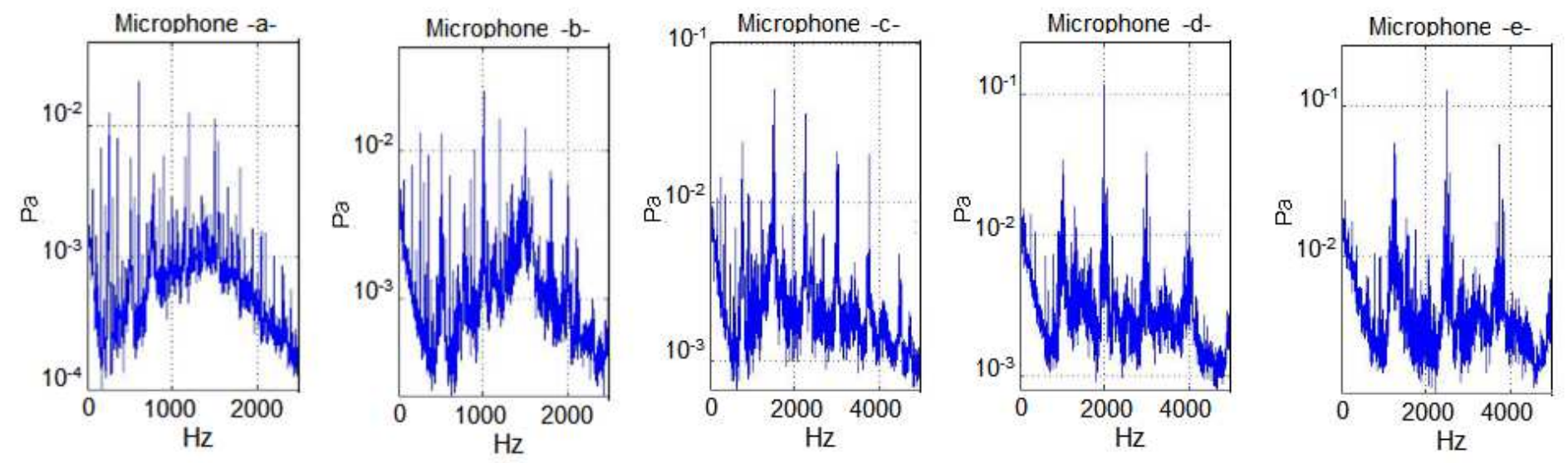

\section{Figure 11}

Results of noise filtering measurement by microphone of the belt SFAT10 with a setting tension $\mathrm{T}=400 \mathrm{~N}$ and torque $\mathrm{C}=25 \mathrm{~N} \cdot \mathrm{m}$ : $\mathrm{a}-\mathrm{N}=500 \mathrm{rpm}, \mathrm{b}-\mathrm{N}=1000 \mathrm{rpm}, \mathrm{c}-\mathrm{N}=1500 \mathrm{rpm}, \mathrm{d}=\mathrm{N}=2000 \mathrm{rpm}, \mathrm{c}-\mathrm{N}=2500$ rpm 

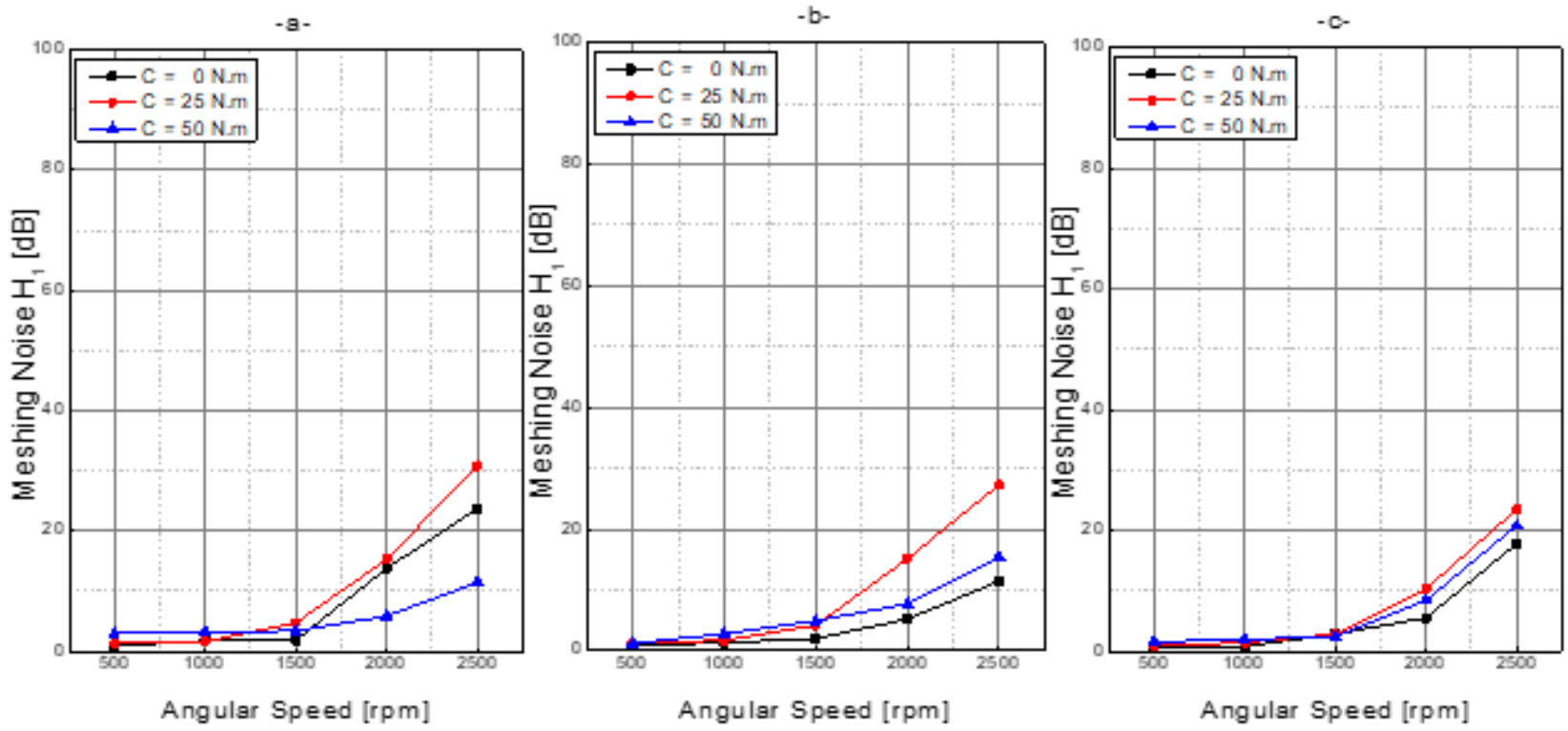

Figure 12

Variation in noise measurement $\mathrm{H} 1$ of the belt AT10 of the three setting tension: $\mathrm{a}-\mathrm{T}=400 \mathrm{~N}, \mathrm{~b}-\mathrm{T}=500 \mathrm{~N}$ et $\mathrm{c}-\mathrm{T}=600 \mathrm{~N}$

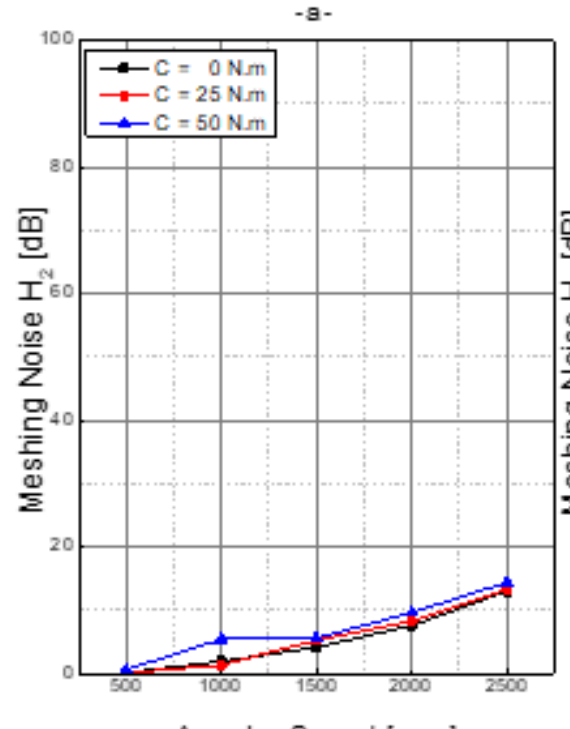

Angular Speed [rpm]

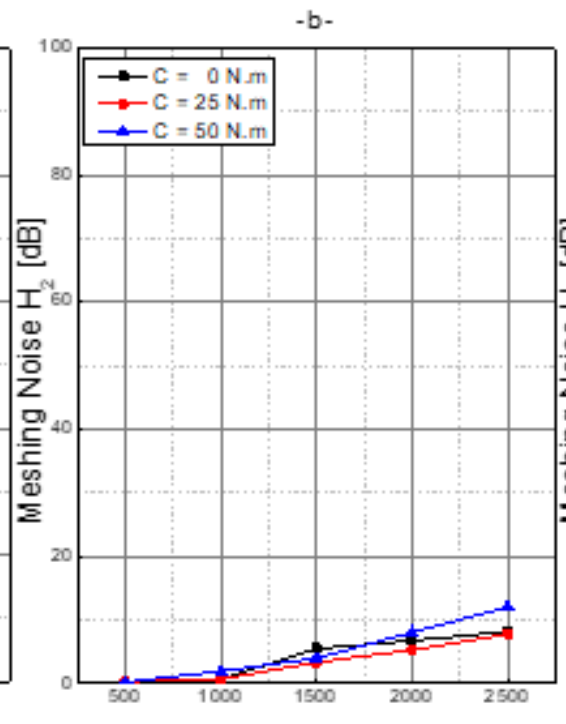

Angular Speed [rpm]

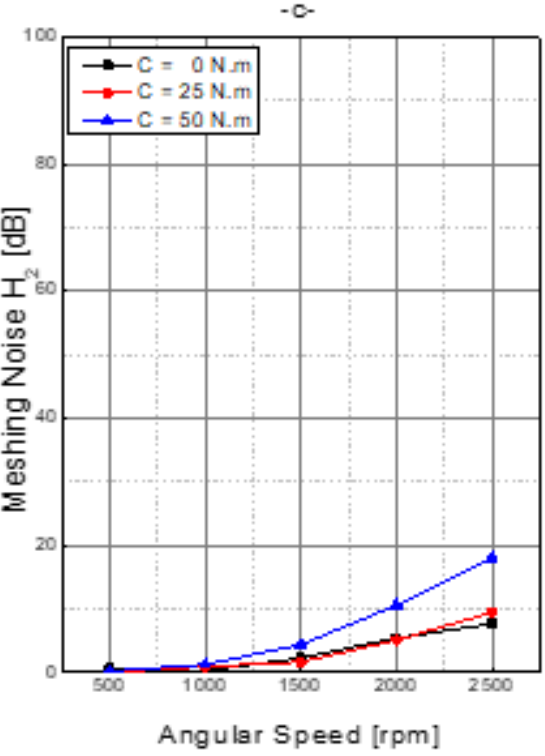

Angular Speed [rpm]

Figure 13

Variation in noise measurement $\mathrm{H} 2$ of the belt AT10 of the three setting tension: $\mathrm{a}-\mathrm{T}=400 \mathrm{~N}, \mathrm{~b}-\mathrm{T}=500 \mathrm{~N}$ et $\mathrm{c}-\mathrm{T}=600 \mathrm{~N}$ 

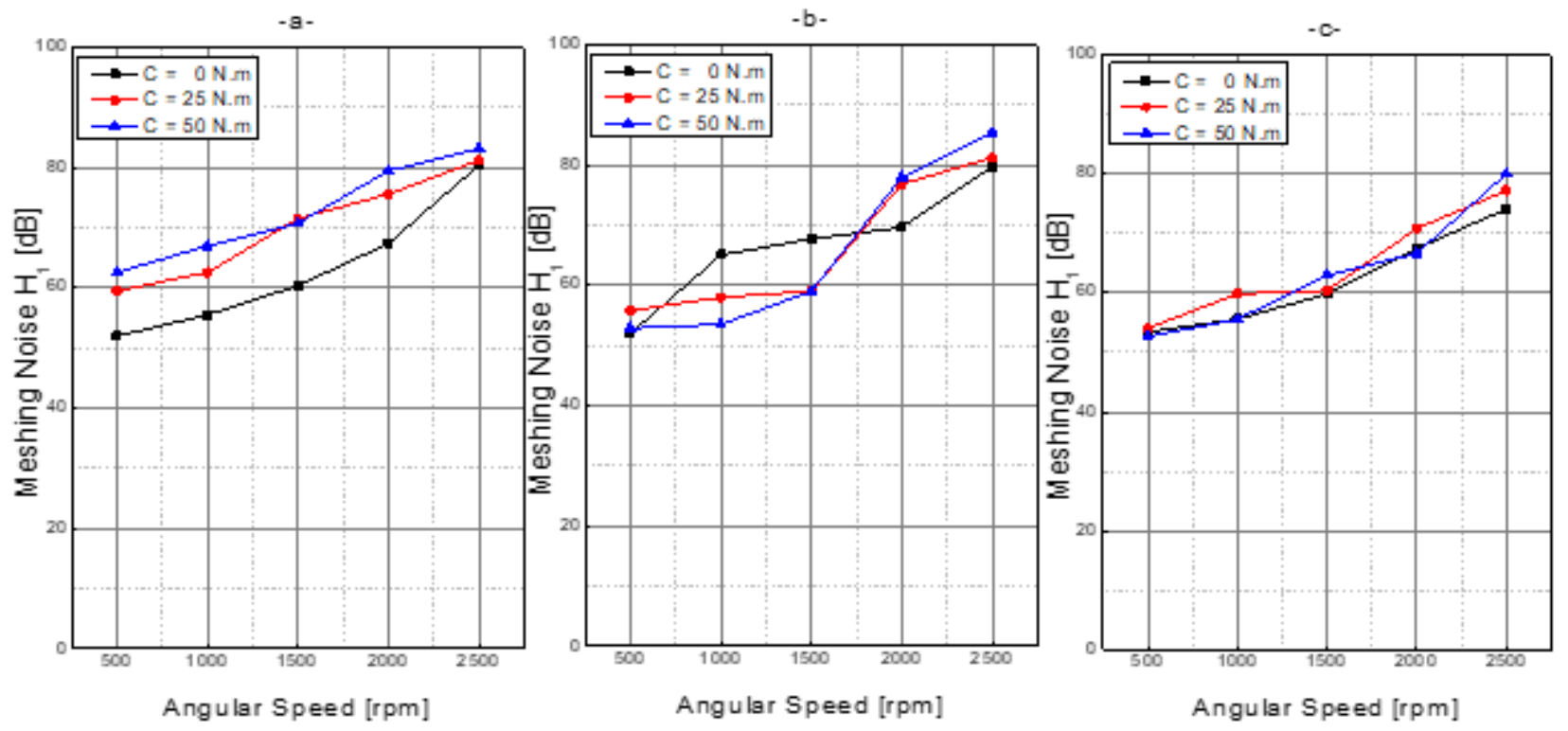

Figure 14

Variation in noise measurement $\mathrm{H} 1$ of the belt BAT10 of the three setting tension: $\mathrm{a}-\mathrm{T}=400 \mathrm{~N}, \mathrm{~b}-\mathrm{T}=500$ $\mathrm{N}$ et $\mathrm{c}-\mathrm{T}=600 \mathrm{~N}$
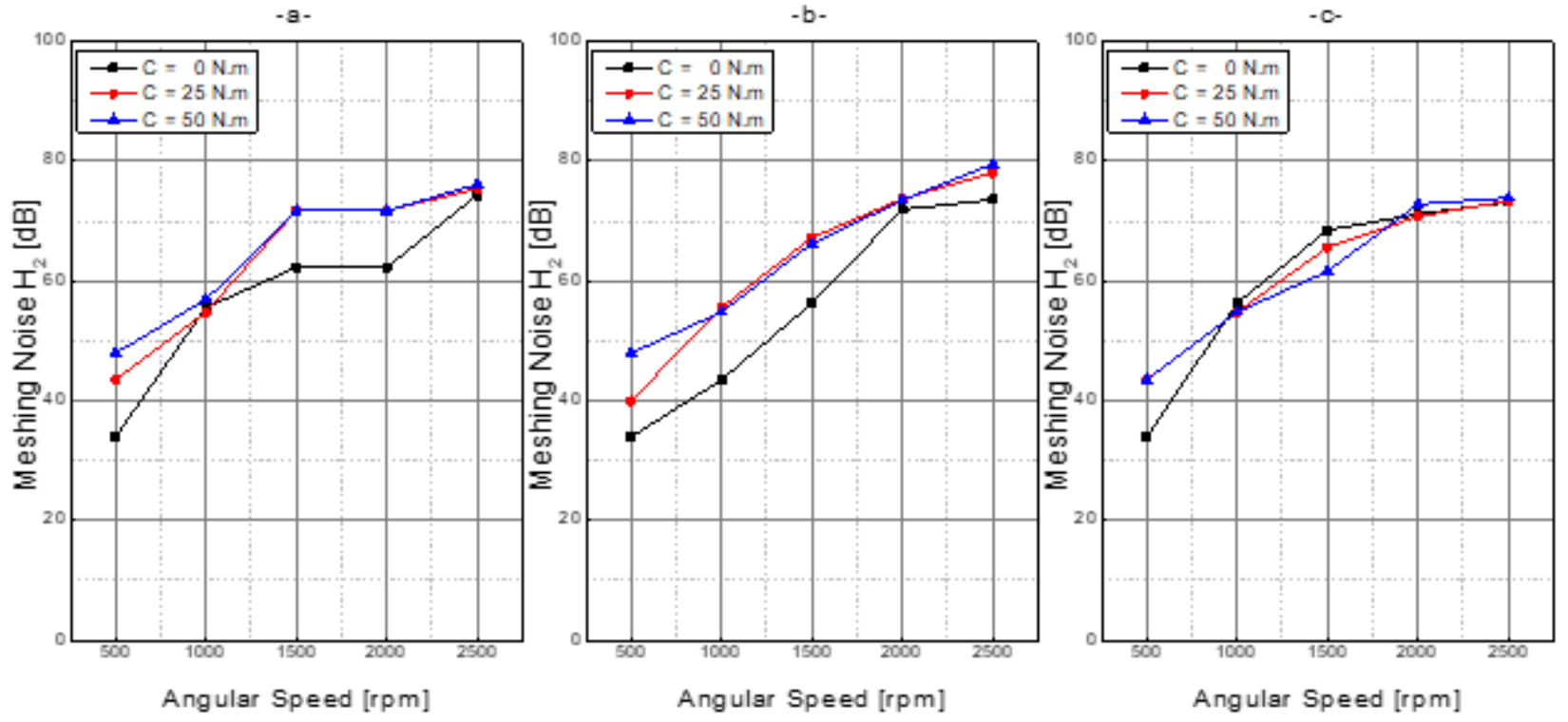

Figure 15

Variation in noise measurement $\mathrm{H} 2$ of the belt BAT10 of the three setting tension: $\mathrm{a}-\mathrm{T}=400 \mathrm{~N}, \mathrm{~b}-\mathrm{T}=500$ $\mathrm{N}$ et $\mathrm{c}-\mathrm{T}=600 \mathrm{~N}$ 

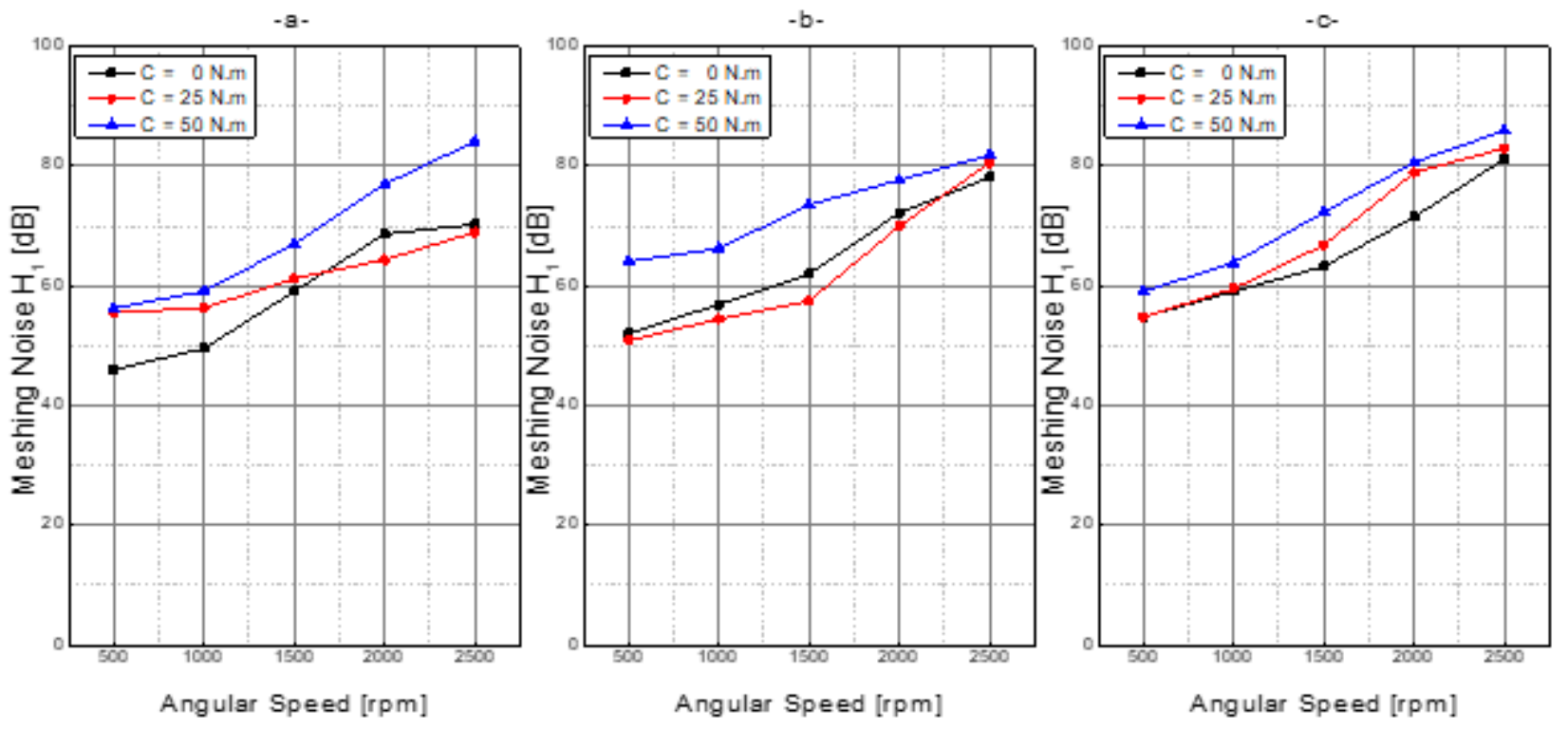

Figure 16

Variation in noise measurement $\mathrm{H} 1$ of the belt SFAT10 of the three setting tension: $\mathrm{a}-\mathrm{T}=400 \mathrm{~N}, \mathrm{~b}-\mathrm{T}=500$ $\mathrm{N}$ et $\mathrm{c}-\mathrm{T}=600 \mathrm{~N}$
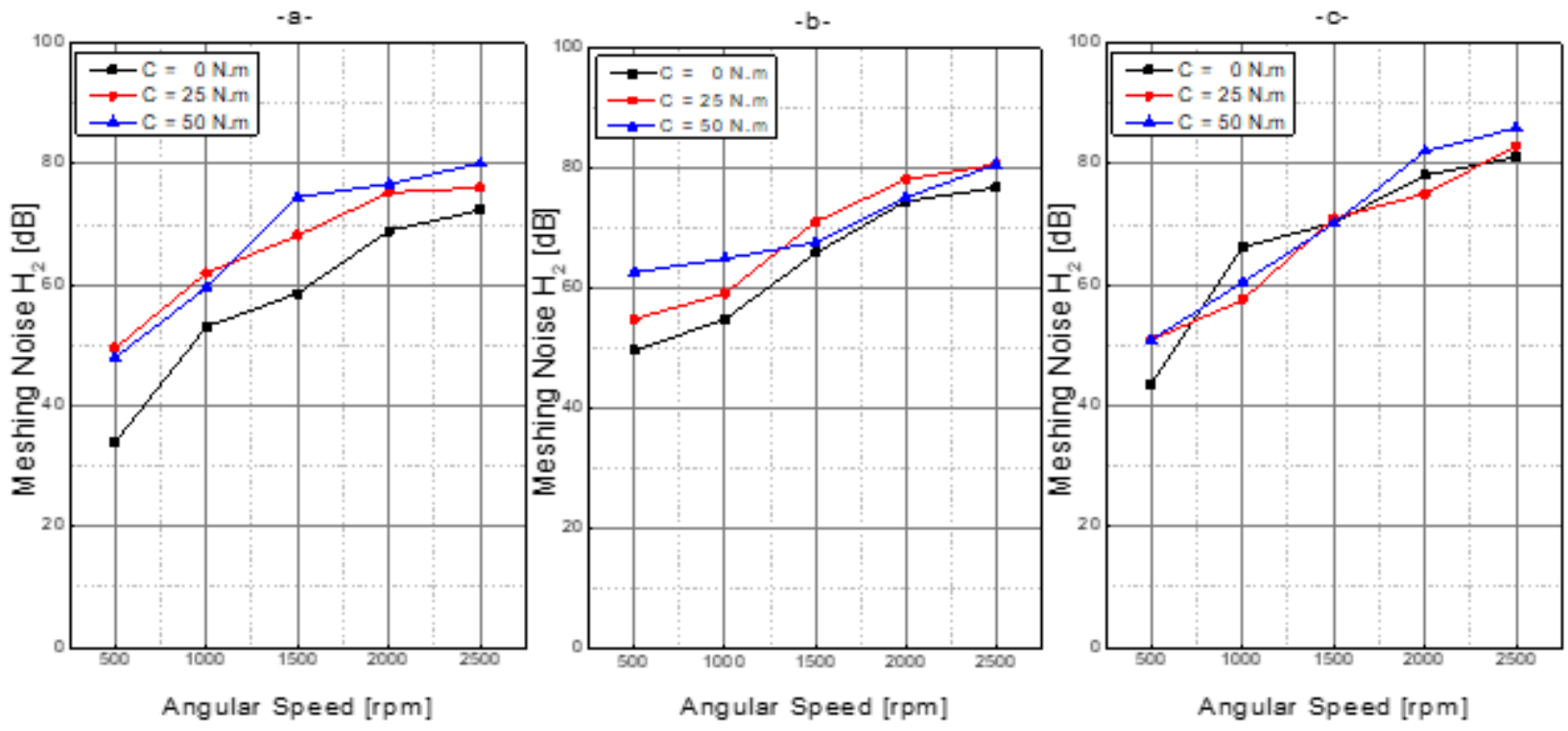

Figure 17

Variation in noise measurement $\mathrm{H} 2$ of the belt SFAT10 of the three setting tension: $\mathrm{a}-\mathrm{T}=400 \mathrm{~N}, \mathrm{~b}-\mathrm{T}=500$ $\mathrm{N}$ et $\mathrm{c}-\mathrm{T}=600 \mathrm{~N}$

\section{Supplementary Files}

This is a list of supplementary files associated with this preprint. Click to download. 
- Acknowledgmentsbruit2020.docx

- Authorscontributions.docx

- BELTNOISE.docx 